\title{
On the reduction of nickel
}

\section{Wöhler \& Liebig}

To cite this article: MM. Wöhler \& Liebig (1832) On the reduction of nickel, Philosophical Magazine Series 2, 11:62, 148-149, DOI: 10.1080/14786443208647702

To link to this article: http://dx.doi.org/10.1080/14786443208647702

册 Published online: 25 Jun 2009.

Submit your article to this journal

III Article views: 3

Q View related articles $₫$ 
solved in muriatic acid without evolving any gas : nevertheless it was not protoxide of iron, but a mixture of protoxide and peroxide, as was ascertained by the increase of weight which it acquired by calcination in the air. The solution of this substance in muriatic acid is yellow; when ammonia is added to it, a black precipitate is formed, which appears brown when it is more divided: it may be filtered and washed in the air without any change of colour, that is to say, without becoming a hydrate of the peroxide, as might be expected. After drying, the precipitate is in small brittle pieces of a black-brown colour, and of a deep brown when powdered: it is a hydrate of a compound of the protoxide and deutoxide, becoming black and losing its water by heat.

This hydrate possesses another unexpected property,-that of being attracted by the magnet as strongly as the intermediate compound, or the magnetic iron ore. If a magnet be immersed in the liquid, while the precipitate is in a state of suspension, a great part of it is collected round the magnet.

Magnetic iron ore acts in a precisely similar way to the artificial substance just described. Some crystals of it were dissolved in muriatic acid, without the contact of air, and the yellow solution was precipitated by ammonia. The same biack precipitate was obtained, which did not oxidize more in the air, and was equally magnetic. It is well known that the white precipitate formed by an alkali in a solution of a protosalt of iron becomes black when it is boiled in the liquid, and it was apparently admitted that this precipitate was anhydrous protoxide of iron: this is a mistake, for it is also a hydrate of the protoxide and peroxide formed by contact of the air during ebullition.

The white protohydrate of iron is not magnetic, at least while it remains in the liquid. 'This fact appears surprising, if it be admitted that in the magnetic compounds of oxides of iron the property of being attracted depends upon the quantity of protoxide which they contain. Reasoning in this way, the hydrate of the protoxide ought to be more magnetic than the bydrate of the mixed oxides.

\section{METHOD OF OBTAINYNG PROTOXIDE OF MANGANESE. BY 'IHE} SAML.

By Arfwedson's method, which consists in heating carbonate of manganese in hydrogen, the protoxide is obtained in a certain and easy manner : it would therefore be useless to describe the following method, if, while it is as easy, it had not also the advantage of producing a protoxide which is unalterable in the air at common temperatures. This method consists in heating together fused chloride of manganese and carbonate of soda, and fusing the mixture at a red heat: when the mass is treated with water, protoxide of manganese is obtained, of a greenish-gray colour.

ON THE REDUCTION OF NICKEL. BY THE SAME.

Richter, as is well known, placed nickel among the noble metals, because he found that its oxide was reduced by the heat of a porce- 
lain furnace. More lately $\mathrm{Gmelin}$ attributed this reduction per se to the presence of gaseous oxide of carbon in the furnace, and assigned the same cause for the reduction of oxide of iron in a porcelain furnace observed by Proust. In fact, it appears contradictory that a metal which oxidizes so readily as nickel, by calcination in the air, which burns in oxygen gas with disengagement of light, and is even susceptible of spontaneous combustion at common temperatures when it is much divided, should be reduced from its oxide merely by the action of a strong heut. Nevertheless, it does not appear that direct experiments have been made on this subject, although it has often been remarked that during the re. duction of nickel in porcelain furnaces, without the use of charcoal, less metal was always obtained when the crucible was well closed. The following experiments will undoubtedly suffice to justify the opinion, that the reduction of rickel per se is only apparent, and that it is in fact due to the oxide of carbon disengaged in the furnace.

Two equal portions of oxide of nickel, equally pure and treated in the same manner, were placed in two crucibles and exposed together to the most intense heat of a porcelain furnace. One of the crucibles was lightly covered, whilst the other was covered internally and externally, with a coating which was vitrifiable by heat; it was not only covered with a smaller crucible, rendered equally impervious to air, but it was put into another of larger dimensions, also covered with a second, and well luted. 'The interval was filled with fine sand. When these crucibles were taken out of the furnace after calcination, that is to say, after a fire of eighteen hours, there was found in that which had been lightly covered nearly five grammes of white metallic malleable nickel, incrusted with much fused and unreduced oxide. On the other hand, in the coated crucible, mere fused oxide was found, or containing only small globules of metal, of the size of a pin's head; and their reduction merely proves that it is inpossible to render a clay crucible impermeable to gases, in a violent and long-continued heat. - Ann. de Chim. et de Phys. xlviii. p. 257.

ANALYSIS OF CAMPHOR AND CAMPHORIC ACID. BY M. LIEBIG. Camphor, taking the mean of two analyses, appeared to consist of

$$
\begin{aligned}
& \text { Hydrogen........... } 9702 \\
& \text { Oxygen............. } 8.535 \\
& \text { Carbon............ } 81.763 \\
& 100 \cdot 000
\end{aligned}
$$

According to Bouillon-Lagrange the camphorates of soda, potash and barytes are so little soluble in water that one part requires from 200 to 300 parts for solption, whilst according to Brandes these salts are deliquescent. According to M. Liebig, these differences depend upon the different kinds of camphoric acid on which the experiments were made.

When camplior is treated with concentrated nitric acid, a yellow liquid 